\title{
AGRESSIVIDADE FISCAL E 0 COMPORTAMENTO DA CHIEF EXECUTIVE OFFICER - CEO FEMININA NO BRASIL
}

\section{TAX AGGRESSIVENESS AND THE BEHAVIOR OF FEMALE CHIEF EXECUTIVE OFFICERS (CEOS) IN BRAZIL}

\section{RESUMO}

Este artigo investiga a relação entre gênero e agressividade do planejamento fiscal. Para tanto, analisamos a transição do Chief Executive Oficcer - CEO masculino para o feminino e a transição do CEO masculino-masculino. As conclusões apresentadas assentam-se em testes com uma amostra extraída do Economática, relativa ao período compreendido entre 2009 e 2014. Foram utilizadas duas métricas a fim de capturar a agressividade fiscal: a primeira, o Book Tax Differences (BTD), que mede a diferença entre o lucro contábil e o lucro tributável das empresas, e a segunda, o Effective Tax Rate (ETR), que mede a taxa de impostos paga em relação ao lucro operacional. Os resultados da nossa pesquisa sugerem que CEOs femininas estão associadas a um planejamento tributário mais suave, indicando menor agressividade fiscal em comparação com seus pares do sexo masculino. A idade constitui um fator que ameniza os dados. Já para as transições de CEO masculino-masculino, não foram encontrados dados estatisticamente relevantes.

Palavras-chave: Planejamento tributário; Agressividade; Fiscal; CEO; Feminina.

\section{ABSTRACT}

This article investigates the relationship between gender and aggressiveness of fiscal planning. To do so, we analyzed Chief Executive Oficcer transitions (male-to-female CEOs and male-to-male CEOs). The conclusions presented are supported by tests with a sample drawn from Economatica in the period 2009-2014. Two metrics were used to capture fiscal aggressiveness: the first, the Book Tax Difference (BTD), which measures the difference between the accounting profit and the taxable profit of the companies, and the second, the Effective Tax Rate (ETR) that measures the tax rate paid in relation to pretax profit. The results of our research suggest that female CEOs are associated with smoother tax planning, indicating less fiscal aggressiveness compared to their male counterparts. Age is a factor that softens the data. As for male-to-male CEO transitions, no statistically significant data were found.

Keywords: Tax planning; tax aggressiveness;CEO; gender.

\begin{abstract}
Regina Maria Nobre Antunes
Mestre em Administração pela FUCAPE Business School (FUNDAÇÃO INSTITUTO CAPIXABA DE PESQUISAS EM CONTABILIDADE, ECONOMIA E FINANÇAS). Especialista em normas IFRS e Normas Internacionais de Auditoria pela FIPECAFI - Fundação Instituto de Pesquisa Contábeis, Atuariais e Financeiras, Pós-Graduada em Controladoria pela FGF - Faculdade da Grande Fortaleza. Graduada em Ciências Contábeis pelo CEUJI- ULBRA - Universidade Luterana do Brasil. Assessora na Contadoria Geral do Banco do Brasil S/A. Contato: Quadra 301, Conjunto 1, Lotes 3,4 e 5. Condomínio Viver Melhor - Samambaia Sul - DF. CEP 72300.531 E-mail: reggina.nobre@hotmail.com.
\end{abstract}

\section{Antonio Lopo Martinez}

Doutorando em Direito (Universidade de Coimbra/ Universidade de Salamanca). Doutor em Contabilidade (Universidade de São Paulo). Contato: Av. Princesa Isabel N. 542 Apt. 1201 Salvador, Ba, 40130 030,

E-mail: antoniolopo@terra.com.br 


\section{INTRODUÇÃO}

Este estudo busca examinar a relação entre gênero e a agressividade do planejamento fiscal, em especial, identificar se as Chief Executive Oficcer - CEOs femininas estão associadas à menor ou maior agressividade fiscal em comparação com seus pares do sexo masculino.

Em primeiro plano, faz-se necessário definirmos o termo agressividade fiscal à luz dos ensinamentos de Hanlon e Heitzman (2010, p. 27), que a definem como "atividades especificamente empreendidas para reduzir impostos ou contrair benefícios fiscais direcionados a fim de redução dos impostos”.

Conforme o entendimento de Francis et al.(2014), a agressividade fiscal constitui um fator importante que reflete o comportamento de altos executivos frente à tomada de decisões em situação de risco; e fornece subsídios para examinar diferenças de gênero para as profissões de gestão.

Com a finalidade de examinarmos a relação entre gênero e agressividade fiscal do CEO da empresa, replicamos com alguns ajustes a metodologia utilizada por Francis et al. (2014, p. 9) e Huang e Kisgen (2012, p. 4), que permite a análise de transição do sexo masculino para o feminino.

Testamos nossa hipótese com uma amostra de 476 itens. Encontramos 16 casos de transição do sexo masculino para o feminino e, ao final, escolhemos, aleatoriamente, 16 empresas de mesmo tamanho e setor e analisamos a transição homem-homem, totalizando 175 observações de transição de CEO. Ao analisar essas amostras, identificamos diferença significativa no período pós-transição que pode ser atribuída à mudança de gênero do CEO da empresa.

Para medir a agressividade fiscal, utilizaremos as métricas de ETR - effective taxe rate- que consiste em avaliar o valor efetivamente pago pelo imposto em relação ao lucro antes do imposto. E a segunda métrica utilizada será o BTD - Book taxe difference, que consiste em observar as diferenças entre o lucro contábil e o lucro tributável das empresas considerando os ativos das empresas.

Para todas as medidas de agressividade fiscal, encontramos uma diminuição no nível de agressividade posterior à transição masculino-feminino. Assim como os estudos de Francis et al. (2014, p. 9), nossa pesquisa indica que os executivos do sexo feminino possuem agressividade fiscal mais suave em comparação com seus pares do sexo masculino.

Para satisfazer nosso estudo, formulamos a seguinte hipótese:

H1: quando há transição de CEO masculino para o feminino, o planejamento fiscal da empresa tende a ser menos agressivo.

Nossa pesquisa sugere que as executivas femininas perseguem estratégias fiscais menos agressivas que seus pares do sexo masculino. Para Francis et al. (2014. p. 5), “o motivo pelo qual as mulheres praticam um planejamento fiscal mais suave, seja provavelmente para evitar riscos adicionais”.

Quanto à escolha de analisar o principal executivo da empresa - CEO e não o CFO - Chieff Financial Officer, esta ocorre em virtude da percepção dos diferentes papéis que cada um desempenha nas empresas brasileiras. Segundo pesquisa realizada pela American Express, no ano de 2014, em conjunto com o CFO Research e Spending Monitor, no Brasil é o principal executivo da empresa que oferece uma visão estratégica para os negócios. E apenas $25 \%$ dos que responderam à pesquisa consideram o CFO como estrategista e 35\%, como catalisador. ( DELOITTE, 2016).

A justificativa para nossa escolha do tema tributário refere-se à resposta ao pedido de Hanlon e Heitzman (2012), que sugere que haja mais pesquisa sobre os impactos individuais dos altos executivos nas estratégias de planejamento fiscal das empresas.

Nesse sentido, o presente estudo mostra-se de grande relevância, pois trata da característica do gestor e a influência que ela exerce sobre a tomada de decisão na empresa. Esse fator é importante de ser destacado, tendo em vista, Huang e Kisgen (2012), concluírem em seus estudos que as finanças corporativas tradicionais ignoram, largamente, a influência que as características específicas do gestor têm sobre as tomadas de decisões, concentrando-se nas características da empresa em vez das características gerenciais dos executivos.

Nosso artigo está estruturado da seguinte forma: primeiramente, fizemos uma revisão de literatura em que enfatizamos a agressividade fiscal e as diferenças de gênero no comportamento de risco e pesquisas anteriores. Nos capítulos seguintes, desenvolvemos a metodologia e coleta de dados, apresentação e análise dos resultados, o teste de sensibilidade e por fim as considerações finais.

\section{REVISÃO DE LITERATURA}

\subsection{Agressividade Fiscal}

Os impostos representam um custo significativo para a empresa e uma redução nos fluxos de caixa disponíveis para a empresa e os acionistas, o que gera incentivos por parte das empresas e acionistas para reduzir impostos por meio de planejamento fiscal agressivo. (CHEN et al., 2010).

É importante observar, conforme entendimento de Francis (et al., 2014, p. 2), que: "posições fiscais agressivas estão sob olhares de auditores e autoridades fiscais”. Em outras palavras, as empresas não buscam ficar na mira do fisco ou até mesmo ter publicidade negativa de seus negócios, portanto, um planejamento fiscal agressivo pode ser repensado caso ponha em risco a reputação da empresa.

Alguns fatores contribuem para um planejamento fiscal mais agressivo, tais como: i) a política de incentivos da empresa ofertada a seus executivos, fator que pode ser minimizado pela boa governança das empresas. Assim, os execu- 
tivos tendem a majorar o lucro como forma de aumentar seus ganhos e bonificações; ii) empresas que dão incentivos de ações a seus gestores os motivam a fazer investimentos arriscados visando maior retorno em sua carteira de ações. Para amenizar esse problema, as empresas devem estruturar benefícios adequados para garantir que os gestores pratiquem uma gestão fiscal eficiente. (DESAI; DHARMAPALA, 2006, p. 30; REGO e WILSON, 2012, p. 6; FRANCIS et al., 2014).

Ao determinar a agressividade tributária, os tomadores de decisão nas empresas estão trocando os custos pelos benefícios. O benefício mais óbvio da agressividade fiscal é a maior economia fiscal. (CHEN et al., 2010).

\subsection{Diferenças de gênero no comportamento de risco}

Para Bharath et al. (2009), o aumento da presença de mulheres em altos cargos executivos tem despertado o interesse em compreender possíveis diferenças nos estilos de tomada de decisão de executivos do sexo masculino e feminino e suas implicações.

De forma geral, a literatura tem explorado as características individuais dos gestores e a influência que elas exercem sobre a gestão das empresas, a exemplo de Dyreng et al. (2010) que concluíram em seus estudos que os executivos, de forma individual, podem provocar incremento na evasão fiscal das empresas que não são explicados simplesmente pela característica destas, mas em grande parte pela característica do gestor. Dyreng et. al. (2010) chamaram essa característica de "efeito executivo", que parece ser um determinante importante para a evasão fiscal das empresas.

Croson e Gnneezi (2009) afirmam em seu estudo que quase todas as decisões que os indivíduos fazem envolvem riscos, em especial no mercado de trabalho, em que estes escolhem caminhos de carreira. O consenso comum é que as mulheres são mais avessas ao risco, sendo isso verdadeiro, essa escolha pode levar as mulheres à menor média salarial, o que explicaria parte da diferença de gênero incondicional nas escolhas de carreira.

Porém, Groson e Gnnezzi (2009) alertam que, mesmo que não existam diferenças reais nas atitudes de gênero em relação ao risco, a crença no estereótipo pode, por si só, trazer implicações para os cargos que são oferecidos às mulheres e, consequentemente, os salários. Em especial trabalhos que exigem decisões arriscadas, como investimentos.

Por sua vez, a aversão ao risco do gestor feminino, retrato na literatura, não significa necessariamente menores lucros para as empresas. Huang e Kisgen (2013, p. 1) analisaram o perfil corporativo de investimentos de mulheres e homens executivos, e constataram que "os investimentos realizados por executivas femininas davam retorno cerca de $2 \%$ maior que os dos executivos do sexo masculino".

Atkinson et al. (2003) sugeriram que as diferenças de gênero, em última instância, têm sua raiz nas preferências individuais. Esses fatores podem influenciar a aversão ao risco diretamente ou em resultados que relacionam diferenças de gênero em relação à riqueza, renda e emprego.

Outros aspectos como acesso à informação e excesso de confiança do gestor podem explicar, ao menos em parte, as diferenças de gênero no modelo de gestão.

Bharat et al. (2009) afirmam que o impacto da informação sobre as tomadas de decisões de investimento tem duas dimensões separadas: as mulheres podem diferir no acesso à informação e podem, também, diferir em sua habilidade ou inclinação para usar a informação disponível, os pesquisadores relatam que os executivos masculinos fazem melhor uso de informações privilegiadas.

Quanto ao fator excesso de confiança, Huang e Kisgen (2012) estudaram o efeito desse fator sobre a tomada de decisão dos executivos e identificaram que "os executivos superconfiantes são mais suscetíveis de serem substituídos, uma vez que decisões excessivamente confiantes levam a resultados que não valorizam os acionistas do ponto de vista da exposição ao risco que essas decisões podem trazer".

O excesso de confiança do principal executivo do sexo masculino pode fazer parecer que as mulheres fazem escolhas mais conservadoras, mas, na realidade, os homens é que se arriscam mais. (HUANG; KISGEN, 2013; FRANCIS et al., 2014).

Por fim, Desai e Dharmapala (2006, p. 1) observam que existem outros fatores, a não ser somente o gênero, que podem influenciar o comportamento fiscal agressivo do CEO, por exemplo, a política de benefícios da empresa, a governança, e as características da empresa.

\subsection{Pesquisas anteriores}

A seguir, traremos alguns estudos sobre a agressividade tributária e a característica do gestor ou do board, e sua influência no planejamento tributário das empresas.

Rego e Wilson (2009) pesquisaram a agressividade fiscal e a remuneração dos executivos. E seus estudos apontaram relação positiva entre o planejamento tributário agressivo e o nível de remuneração dos Ceos.

Os pesquisadores, ainda, quiseram saber se essa relação positiva entre a renda dos executivos e o planejamento tributário agressivo devia-se a uma contratação ótima ou os executivos estavam comprometendo as receitas da empresa em longo prazo.

Todavia, restou provado em seus estudos que, mesmo em empresas com fraca governança, não houve evidências que um planejamento tributário agressivo poderia comprometer o desempenho das empresas no futuro, levando a crer que os resultados do planejamento tributário agressivo eram consistentes ao longo dos anos.

Lanis e Richardson (2011) pesquisaram o efeito da composição do conselho de administração na agressividade tributária das empresas. Para tanto, utilizaram uma amostra baseada na escolha de 32 corporações compreendendo 16 
corporações com planejamento fiscal agressivo e 16 empresas consideradas não agressivas tributariamente, os resultados revelaram que a inclusão de uma proporção maior de membros externos no conselho de administração reduz a probabilidade de agressividade fiscal. Dessa forma, os resultados indicam que o efeito de interação entre a composição do conselho de administração, no caso, uma maior proporção de conselheiros independentes no conselho, e o estabelecimento de um sistema eficaz de gerenciamento de riscos e controles internos reduzem a agressividade tributária.

Richardson et al. (2013) ainda examinaram o impacto das características de supervisão do conselho de administração na agressividade dos impostos corporativos. Com base em um conjunto de 203 empresas australianas listadas publicamente no período de 2006-2009, os resultados da regressão revelaram que, se uma empresa estabelece um sistema eficaz de gerenciamento de riscos e controles internos, contrata uma empresa de auditoria das chamadas big four (big-4), ou seja, uma das quatro maiores empresas de auditoria do mundo, o trabalho do auditor interno tende a ser mais independente e, quanto mais independente é o seu comitê de auditoria interna, é menos provável que seja fiscalmente agressivo.

ZemZem et al. (2013) pesquisaram os efeitos das características do conselho de administração na agressividade tributária na França. A análise é feita com base em uma amostra de 73 empresas francesas listadas no índice SBF 120 para o período 2006-2010. Os resultados apontaram que o tamanho e a porcentagem de mulheres no conselho afetam a atividade de agressividade tributária. Outros fatores como o Retorno sobre ativos e o tamanho da firma estão significativa e positivamente associados.

Em geral, o estudo fornece insights exclusivos sobre a associação entre diversidade de diretoria e agressividade tributária.

Francis et al. (2014), pesquisaram sobre o gênero e a agressividade fiscal, sob o ponto de vista do CFO da empresa dos EUA. Utilizaram banco de dados da EXEcucomp database, entre os anos de 1988 a 2007 e encontraram 92 casos de transição homem-mulher e 48 de mulher-homem. E o resultado sugere que os CFOs do sexo feminino são cerca de $17.4 \%$ menos propensos a se envolverem em comportamentos de planejamento fiscal agressivo em comparação com seus colegas do sexo masculino.

Por conseguinte, nosso trabalho supre essa lacuna de pesquisa em solo brasileiro quanto ao tema estilo de gestão e planejamento tributário, possibilitando um estudo sobre o comportamento de gênero no perfil de gestão de algumas das principais empresas brasileiras de capital aberto.

\section{METODOLOGIA E COLETA DE DADOS}

Para examinar o efeito do gênero sobre a agressividade do planejamento fiscal, comparamos os graus de agressividade fiscal no período pós-transição masculino-feminino do principal executivo da empresa, para tanto, utilizamos a base de dados do software Economática. Selecionamos as Companhias abertas sediadas no Brasil que possuem mulheres no comando. E realizamos, também, um teste de sensibilidade com transição do Ceo homem-homem no comando das empresas, bem como analisamos os anos em que não há transição de Ceo, para identificarmos possíveis diferenças de gênero quanto à agressividade do planejamento fiscal.

Iniciamos a pesquisa proposta neste artigo com uma população constituída de 476 empresas e, ao fim, selecionamos 22 que possuíam mulheres no comando no período em estudo e 54 que possuíam executivos homens.

Empresas que não apresentaram dados suficientes para análise no período, foram excluídas, restando, ao final, 16 empresas que possuíam mulheres no comando. Selecionamos mais 16 empresas de semelhante tamanho e área de atuação cujo CEO era do sexo masculino para um teste de sensibilidade, totalizando 32 empresas analisadas e 175 observações.

O período compreendido para coleta de dados relativa à pesquisa apresentada neste artigo, referiu-se aos anos de 2009 a 2014 e, para identificarmos o gênero do principal executivo da empresa e o período em que esteve à frente dos negócios da companhia, analisamos o formulário de referência disponível nos arquivos da CVM e no próprio site das empresas por meio da seção "relação com investidores".

Uma das principais limitações desse artigo consistiu, justamente, no número reduzido de mulheres que atuam no comando das grandes empresas no Brasil. Uma das explicações possíveis para esse fato refere-se ao que a literatura chama de "teto de vidro".

Para Madalozo (2011), o conceito “teto de vidro” ou glassceiling teve início nos Estados Unidos, na década de 1980, e significa que os critérios para promoção nem sempre são transparentes. De acordo com Madalozo (2011), "a falta de transparência acaba criando uma barreira invisível que afeta a progressão de carreira por parte do público feminino”.

\subsection{Modelo}

Para capturarmos a agressividade fiscal, foram utilizadas duas variáveis dependentes: a ETR - efetive taxe rate e o BTD - book taxe difference.

Na lição de Chen et al. (2010), o ETR constitui "à medida que reflete o planejamento fiscal por meio da diferença entre o imposto pago e o lucro antes dos impostos”. E o BTD, segundo lição de Hanlon e Heitzman (2010), refere-se, conceitualmente, à “diferença entre a base tributável e o resultado contábil”.

Para dar mais robustez ao modelo, acrescentamos as seguintes variáveis de controle: Índice de alavancagem, 
Retorno sobre os Ativos, Tamanho, Idade e Gênero. Dentre as quais destacamos a varíavel (ROA) que mede o desempenho da empresa, e é definida como a razão entre o lucro operacional e o total de ativos.

Para Dyreng et al. (2008), as empresas estão interessadas em otimização fiscal para melhorar o desempenho dos negócios. Essa variável é usada para controlar o desempenho e destacar o efeito específico da otimização fiscal.

Outra variável que destacamos é a variável (TAM). Hanlon \& Slemrod (2009) confirmam a existência de um relação positiva entre tamanho da empresa e taxa de imposto efetiva. Resumimos as demais variáveis independentes no Quadro 1 , que traz a descrição de todas as variáveis utilizadas em nosso estudo.

Quadro 1 - Variáveis de Controle

\begin{tabular}{|c|c|}
\hline Medida & \\
\hline LEV - leverage & Índice de alavancagem - medido como a dívida de longo prazo, dividida pelo ativo do ano anterior. \\
\hline $\mathrm{ROA}$ - return on assets & Retorno sobre os ativos - medido pelo lucro operacional da empresa, dividido pelo ativo do ano anterior. \\
\hline TAM - size & Logaritmo natural do valor de mercado da empresa i, no início do ano t. \\
\hline IDADE & Variável de interação com a dummy de gênero. \\
\hline GÊNERO & $\begin{array}{c}\text { Gênero do CEO da empresa assumirá } 1 \text { quando houver transição macho-fêmea, e zero quando não } \\
\text { houver transição. }\end{array}$ \\
\hline
\end{tabular}

Fonte: Os autores.

Nossa hipótese:

H1: Quando da transição do CEO masculino para o feminino, o planejamento fiscal da empresa tende a ser menos agressivo.

Para satisfazer nossa primeira hipótese (H1), construímos a seguinte equação:

AgreFiscal i, $t=\beta 0+\beta 1$ CEOFEMi, $t+{ }^{*}$ CEOIDADE $+\beta 3$ TAMi, $t+\beta 4$ ROAi, $t+\beta 5 L E V i, t+\varepsilon i, t(1)$.

AgreFiscal i, t representa as duas proxies de agressividade fiscal, para empresa i no ano t. São elas o ETR. Segundo Chen et al., "essa medida reflete o planejamento fiscal por meio da diferença entre o imposto pago e o lucro antes dos impostos". Quanto menor o índice, mais agressiva será a empresa em seu planejamento fiscal, e a segunda é o BTD, que consiste na diferença entre a base tributável ou fiscal e o resultado contábil, o BTD tornou-se cada vez mais utilizado como uma proxy para a agressividade fiscal na literatura contábil, (CHEN et al., 2010; FRANCIS et al., 2014, p. 12).

Para Chen et al. (2010), "como a diferença tributária pode ser resultado da gestão de resultados e do planejamento tributário, essa proxy revela, pelo menos em parte, a diferença tributária causada pelas atividades de gestão de resultados". Quanto maior o índice do BTD, mais agressiva a empresa em sua política de planejamento fiscal.

A variável CEOFEM é a nossa variável dummy, que, a exemplo de Francis et al. (2014, p. 11), "captura efeito do gênero do CEO sobre a agressividade fiscal, o que equivale a um (1) se houver transição do CEO no ano (macho-fêmea), e zero (0)se não houver transição".

Já a variável CEOIDADE consiste na variável de interação com a variável dummy de gênero, queremos saber se a idade influencia no posicionamento de risco da mulher, refletindo o planejamento tributário.

De acordo com Francis et al. (2014, p. 13), empresas de alto crescimento têm mais investimentos que geram aumento da evasão fiscal, portanto, maiores chances de praticarem o planejamento fiscal agressivo; assim, controlamos o tamanho da empresa (TAMi, t) a variável TAM é o Ativo Total da empresa i no ano t, pela qual identificamos o tamanho da empresa.

Também controlamos por ROA que é o retorno sobre os ativos para a empresa i no ano t, medido como o lucro operacional dividido pelo Ativo do ano anterior.Chen et al. (2010) traçam uma relação direta entre empresas lucrativas e planejamento tributário, de acordo com os autores empresas mais lucrativas tendem a ter maiores incentivos para o planejamento tributário.

Por fim, incluímos a variável de controle LEV - LEVERAGEi, t nas regressões, essa variável retrata a alavancagem para a empresa i no ano $t$, calculado como dívida de longo prazo e dividido pelos ativos do ano anterior. Conforme os estudos de Francis et al. (2014, p. 13), "empresas mais alavancadas são menos propensas a envolver-se em planejamento fiscal agressivo por causa dos benefícios fiscais de financiamento da dívida".

\section{APRESENTAÇÃO E ANÁLISE DOS RESULTADOS}

As amostras utilizadas neste estudo foram retiradas da base de dados do software Economática no período compreendido entre 2009 a 2014. Após, exportamos as 476 empresas da base do Economática para o Excel com o fim de trabalharmos os dados, assim, analisamos individualmente todas as empresas via Formulário de Referência com o objetivo de identificarmos a data da posse e o gênero do principal executivo da empresa.

Na coleta de dados, identificamos 16 casos de transição homem-mulher e selecionamos mais 16 casos de transição homem-homem com empresas de mesmo porte e ramo para realizarmos um teste de robustez. No total identificamos 32 casos de transição de executivo-gênero e mais de 175 observações. 
Calculamos, então, as métricas utilizadas nas variáveis de controle: BTD, ETR, LEV, ROA, TAM e idade dos executivos para cada uma das empresas/ano e, com o resultado dessas variáveis, montamos a regressão descrita na metodologia.

Como podemos observar, A Tabela 1 traz a variável dummy CEOFEM que representa a transição de CEO masculino-feminino e seu comportamento com as demais variáveis de controle.

Tabela 1 - Estatística descritiva das variáveis utilizadas na regressão

\begin{tabular}{cccccc} 
Variável & Nr. de Obs. & Média & Desvio Padrão & Mín. & Máx. \\
\hline ETR & 95 & 0,0474367 & 0,1103958 & $-0,0872143$ & 0,3431144 \\
BTD & 96 & $-0,4290574$ & 1,52261 & $-60,357622$ & 0,6041038 \\
CEOFEM & 96 & 0,4375 & 0,4986825 & 0 & 1 \\
IDADE & 96 & 50,44792 & 70,592059 & 38 & 63 \\
LEV & 95 & 0,3452391 & 0,4894896 & 0 & 0,405565 \\
ROA & 95 & $-0,6169479$ & 2,030712 & 8,346199 & 8,668996 \\
TAM & 96 & 5,023787 & 2,185994 & 1,122445 \\
\hline
\end{tabular}

Fonte: Os autores.

Observa-se, na Tabela 1, uma relação direta da característica CEO feminina com a maioria das variáveis. É possível identificar, pela tabela, que as empresas com CEOS femininos no comando possuem, em geral, um valor positivo para o ETR, indicando que pagam mais impostos, portanto, os resultados sugerem que uma mudança para um CEO feminino faz com que a empresa seja menos agressiva (ETR maior). A idade constitui um fator que ameniza os resultados, tendo em vista o coeficiente da idade (CEOIDADE) ser negativo.

Para a variável BTD, a relação é inversa, o que indica que, quando há mudança para executiva feminina, reduz-se o BTD. Portanto, reduz-se a agressividade fiscal da empresa. A idade da mulher ameniza esse fato.

A seguir, apresentamos a Tabela 2, que mostra a correlação entre as variáveis de controle:

Tabela 2 - A correlação entre as variáveis

\begin{tabular}{|c|c|c|c|c|c|c|c|}
\hline & ETR & BTD & CEOFEM & IDADE & LEV & ROA & TAM \\
\hline ETR & 1,000 & & & & & & \\
\hline BTD & 0,1454 & 1,000 & & & & & \\
\hline CEOFEM & $-0,0205$ & 0,0932 & 1,000 & & & & \\
\hline IDADE & 0,0432 & 0,1074 & 0,3569 & 1,000 & & & \\
\hline LEV & 0,0250 & $--0,3863$ & 0,2153 & $--0,1619$ & 1,000 & & \\
\hline ROA & 0,1461 & 0,9023 & 0,1249 & 0,1524 & $-0,3493$ & 1,000 & \\
\hline TAM & 0,3274 & 0,5448 & 0,0084 & 0,1495 & $-0,0665$ & 0,5171 & 1,000 \\
\hline
\end{tabular}

Analisando a Tabela 2, nota-se que existe correlação significativa entre as variáveis.

Em especial, as variáveis LEV com correlação negativa, com as variáveis BTD (-0,3863) e IDADE (-0,1619). Inferimos, em relação à variável BTD, que, quanto mais alavancada a empresa, menos ela pratica o planejamento fiscal agressivo, esse resultado está em conformidade com os registros da literatura recente, a exemplo de Francis et al. (2014, p. 13) que afirmaram em seus estudos que "empresas mais alavancadas são menos propensas a envolver-se em planejamento fiscal agressivo por causa dos benefícios fiscais de financiamento da dívida”.

Quanto à variável idade, o resultado de correlação sugere que, quanto maior a idade da mulher, menor a prática da alavancagem financeira, essa interpretação está em consonância com os estudos de Chen et al. (2010) que indicam que "mulheres fazem menos aquisições que homens e empresas comandadas por mulheres crescem mais lentamente, mas, quando fazem aquisições e investimentos, os retornos são mais elevados que seus pares masculinos".

Por sua vez, como correlação positiva direta, nos chama a atenção as variáveis ROA (0. 9023) e TAM (0. 5448) em relação ao BTD. O que nos leva a inferir, por meio da variável ROA, que captura os retornos sobre os Ativos, que empresas mais rentáveis praticam mais a agressividade fiscal, conforme Chen et al. (2010): "de acordo com os autores empresas mais lucrativas tendem a ter maiores incentivos para o planejamento tributário agressivo”. 
Por fim, a variável TAM, que controla o tamanho da empresa, é direta e positivamente relacionada com a variável BTD, resultado que sugere que, quanto maior a empresa, mais atividades de planejamento fiscal ela pratica. Francis et al. (2014, p. 13) registram que: "empresas de alto crescimento têm mais investimentos que geram aumento da evasão fiscal, portanto maiores chances de praticarem o planejamento fiscal agressivo".

Na próxima tabela, analisamos a variável dependente ETR:

Tabela 3 - Regressão variável dependente ETR

\begin{tabular}{ccccc}
\hline ETR & Coef, & STd, Err, & z & P>IzI \\
\hline CEOFEM & 0,2202829 & 0,0916567 & 2,40 & 0,016 \\
CEOAGE &,- 0042548 & 0,0017648 & 2,41 & 0,016 \\
LEV & 0,0036902 & 0,0282891 & 0,13 & 0,896 \\
ROA & 0,0005645 & 0,0054527 & 0,10 & 0,918 \\
TAM & 0,0155284 & 0,012001 & 1,29 & 0,196 \\
\hline
\end{tabular}

Fonte: Dados da pesquisa/ Elaboração: Os autores.

Ao realizarmos o teste de Hausman (1978), que permite discriminar os efeitos fixos e aleatórios, percebemos que a tabela da variável ETR deveria ser apresentada em painel com efeitos aleatórios conforme acima e as variáveis foram winsorizadas a $5 \%$.

O coeficiente CEOFEM é de 0,2202829 e mostra-se estatisticamente significativo no nível de 5\%. Pelo sinal positivo do indicador CEOFEM, inferimos que as empresas brasileiras que possuem CEO feminina no comando são menos agressivas em seu planejamento fiscal (ETR maior). Assim, o resultado é significativo e consistente com nossa hipótese e está de acordo com os estudos de Francis et al. (2014, p. 9) "que sugerem que os executivos do sexo feminino são menos propensos a se envolver em comportamentos fiscal agressivo, em comparação com os seus homólogos masculinos”.

A idade é fator que ameniza esse dado, tendo em vista que a variável de interação com a idade tem coeficiente negativo $(-0,0042548)$. Ou seja, com o avanço da idade, as mulheres executivas tendem a praticar planejamento fiscal mais agressivo.

A seguir, analisamos a tabela da variável dependente BTD.

Tabela 4 - Variável dependente BTD

\begin{tabular}{ccccc}
\hline BTD & Coef, & STd, Err, & t & P>ItI \\
\hline CEOFEM & $-1,952512$ & 0,6901593 & $-2,83$ & 0,006 \\
CEOAGE & 0,391071 & 0,013382 & 2,92 & 0,005 \\
LEV & $-0,7776369$ & 0,2321 & $-3,35$ & 0,001 \\
ROA & 0,3470778 & 0,441487 & 7,86 & 0,000 \\
TAM & $-1,237,855$ & 0,2340482 & $-5,29$ & 0,000 \\
\hline
\end{tabular}

Fonte: Dados da Pesquisa / Elaboração: Os autores.

Ao realizamos o teste de Hausman (1978) de efeitos robustos, indicou que a tabela da variável BTD deveria ser apresentada em painel com efeitos fixos conforme acima. As variáveis foram winsorizadas a $5 \%$.

Analisamos a variável BTD, em um intervalo de confiança de 95\%, os resultados apontaram para um coeficiente negativo na dummy CEOFEM (-1,952512), indicando que, quando há mudança para uma CEO feminina, reduz-se o BTD, portanto, reduz-se a agressividade fiscal da empresa. Da mesma forma que observamos na variável ETR, a idade da mulher ameniza esse fato, coeficiente CEOAGE significativo a 5\% (pvalor de 0,005) e positivo conforme esperado:> 0391071 (o mesmo que 3. 9\%), demonstrando que, quanto maior a idade das mulheres, mais elas praticam planejamento fiscal agressivo. Os resultados estão de acordo com os estudos recentes na área tributária, a exemplo de Francis et al. (2014), que afirmam que "a aversão ao risco do sexo feminino é provavelmente uma razão importante por trás do efeito de gênero documentado sobre a agressividade fiscal”.

\section{TESTE DE SENSIBILIDADE}

O Objetivo do teste de sensibilidade é avaliarmos a transição do homem no comando das empresas. Para tanto, realizamos uma regressão com mais 16 empresas de tamanho e área de atuação semelhante ao da nossa regressão principal em que analisamos, anteriormente, a transição mulher-homem. A variável CEOMASC é a nossa variável dummy, que 
captura a transição do Ceo masculino sobre a agressividade fiscal, o que equivale a um (1) se houver transição do CEO no ano (homem-homem), e zero (0) se não houver transição.

Nossa hipótese:

H2: Quando da transição do Ceo masculino -masculino não há alteração no nível de agressividade do planejamento fiscal.

Para satisfazer nossa segunda hipótese (H2), construímos a seguinte equação:

Agresi, $\mathrm{t}=\beta 0+\beta 1 \mathrm{CEOMASCi}, \mathrm{t}+{ }^{*} \mathrm{CEOIDADE}+\beta 3$ TAMi, $\mathrm{t}+\beta 4 \mathrm{ROAi}, \mathrm{t}+\beta 5 \mathrm{LEVi}, \mathrm{t}+\varepsilon \mathrm{i}, \mathrm{t}(2)$.

Em que, AgreFiscali, t representa as duas proxies de agressividade fiscal, para empresa i no ano t. São elas o ETR. Segundo Chen et al., "essa medida reflete o planejamento fiscal por meio da diferença entre o imposto pago e o lucro antes dos impostos”. Quanto menor o índice, mais agressiva será a empresa em seu planejamento fiscal, e a segunda é o BTD, que Chen et al. (2010) definem como "a diferença tributária pode ser resultado da gestão de resultados e do planejamento tributário, essa proxy revela, pelo menos em parte, a diferença tributária causada pelas atividades de gestão de resultados". Quanto maior o índice do BTD, mais agressiva a empresa em seu planejamento fiscal.

A variável CEOMASC é a nossa variável dummy, que captura a transição do Ceo masculino sobre a agressividade fiscal, o que equivale a um (1), se houver transição do CEO no ano(homem-homem), e zero (0), se não houver transição".

Já a variável HH_IDADE é a variável de interação idade com a variável dummy de gênero masculina. Queremos saber se a idade influencia o posicionamento de risco do executivo masculino, refletindo o planejamento tributário.

Como variáveis de controle, utilizaremos (TAM, ROA e LEV), com o fim de controlarmos, respectivamente, o Tamanho, o Retorno sobre os Ativos e a Alavancagem das empresas analisadas.

Não conseguimos controlar a transição de Ceo mulher-mulher por não haver registros na amostra analisada.

\subsection{Análise dos Resultados do Teste de Sensibilidade Masculino}

Tabela 5 - Regressão variável dependente ETR

\begin{tabular}{ccccc}
\hline ETR & Coef. & STd. Err. & Z & P>IzI \\
\hline CEOHH & 0,0773514 & 0,111295 & 0,70 & 0,487 \\
HH_Idade & $-0,00183$ & 0,0031354 & $-0,58$ & 0,559 \\
LEV & $-0,001845$ & 0,0193875 & $-0,10$ & 0,924 \\
ROA & $-0,0084673$ & 0,0047996 & $-1,76$ & 0,078 \\
TAM & 0,0683318 & 0,0368836 & 1,85 & 0,064 \\
IDADE & $-0,0004412$ & 0,0005516 & $-0,80$ & 0,424 \\
\hline
\end{tabular}

Fonte: Dados da pesquisa/Elaboração: Os autores.

O teste de Hausman (1978) que permite discriminar os efeitos fixos e aleatórios indicou que deveríamos apresentar os resultados do painel, com efeitos aleatórios. As variáveis foram winsorizadas a $5 \%$.

Conforme Tabela 5, coeficiente CEOHH e HH_idade foram estatisticamente insignificantes: CEOHH, coeficiente $(0,0773514)$ e pvalor $(0,487)$ e HH_idade coeficiente $(-0,00183)$ e pvalor $(0,559)$, portanto, iguais a zero. Inferimos, com base nos resultados, que qualquer mudança de CEO, considerando-se, apenas, o gênero masculino homem-homem e a idade do executivo, não gera efeito sobre a política fiscal quando $\mathrm{y}=\mathrm{ETR}$.

Tabela 6 - Variável dependente BTD

\begin{tabular}{ccccc}
\hline BTD & Coef, & STd,Err, & Z & P>IzI \\
\hline CEOHH & 72878,01 & 92109,23 & 0,79 & 0,429 \\
HH_Idade & $-1679,754$ & $-2351,789$ & $-0,71$ & 0,475 \\
LEV & $-8,555,922$ & 19143,29 & 0,45 & 0,655 \\
ROA & $-4445,816$ & 3571,64 & $-1,24$ & 0,213 \\
TAM & $-3347,558$ & 29107,64 & 0,12 & 0,908 \\
IDADE & $-57,5499$ & $-471,3639$ & 0,12 & 0,903 \\
\hline
\end{tabular}

Fonte: Dados da pesquisa/ Elaboração: Os autores.

O teste de Hausman (1978) indicou que devemos apresentar os resultados da Tabela 6 do painel, com efeitos aleatórios conforme Tabela 6 . 
Coeficiente mudHH e HH_idade para o BTD não são significativos. Novamente, como aconteceu com o ETR, são estatisticamente iguais a zero.

\section{CONSIDERAÇÕES FINAIS}

Após a análise dos dados, o resultado do teste de nossa hipótese (H1) sugere que as mulheres são menos agressivas que os homens, pois, na mudança de CEO masculino para o feminino, tivemos redução na agressividade fiscal, nas duas métricas utilizadas para medir a agressividade fiscal: o ETR e o BTD. Também ficou evidenciado que o fator idade ameniza esse dado, ou seja, quanto mais idade tiver a executiva, maior a chance de praticar um planejamento fiscal agressivo.

Em seguida, como teste de sensibilidade, analisamos a transição do Ceo masculino-masculino e os resultados revelaram que não há alteração na agressividade do planejamento fiscal. Após análise dos dados, não foram identificados resultados estatisticamente relevantes para a transição masculino-masculino tendo em vista as duas métricas de agressividade fiscal que foram utilizadas: ETR e BTD. Além disso, analisamos, também, os anos em que não houve transição do Ceo e não foram encontrados resultados estatisticamente relevantes na amostra.

Com base nos resultados, observamos que a gestão feminina nas empresas produz um planejamento fiscal mais suave, e sugere que as CEOS femininas nas empresas brasileiras perseguem estratégias tributárias menos agressivas que seus homólogos masculinos. Entendemos ser oportuno o tema em questão, pois seus resultados poderão influenciar as decisões de contratação nas empresas brasileiras. Uma vez que resta caracterizado o perfil de planejamento fiscal da CEO feminina, é de se esperar, por exemplo, que empresas que tendem a evitar riscos prefiram contratar executivas mulheres.

Assim, os estudos indicam que as características individuais do Ceo importam no momento do planejamento fiscal das empresas, tendo em vista as diferenças de gênero documentadas na literatura em relação à: tolerância ao risco, ao excesso de confiança, uso da informação privilegiada, nível de conhecimento, etc.

Uma vez estabelecido que homens e mulheres difiram quanto à política corporativa, a tendência é que empresas procurem por CEO femininas caso desejem esse perfil.

Ao apresentarmos os resultados desta pesquisa, espera-se contribuir com o tema tributário e o debate sobre as diferenças de gênero nas organizações no Brasil.

As fragilidades e limitações encontradas a princípio referem-se ao percentual de mulheres em cargos executivos no Brasil, umas das explicações para esse fato pode estar no que a literatura de gênero denomina de glass ceiling, ou "teto de vidro". Trata-se de uma barreira invisível que impede as mulheres de chegarem ao topo da hierarquia corporativa.

Cabe ressaltar que os resultados apresentados se referem às Companhias analisadas e ao período apresentados, e as variáveis de controle analisadas não exaurem a amplitude do tema tributário ou das influências do gênero na tomada de decisão nas empresas, mas abre um campo para discussão e proposição de mudanças.

Ademais, sugerimos, para pesquisas futuras, que seja analisado o tema tributário e gênero, considerando outros aspectos como formação, setor empresarial, leis e regulamentos, tendo em vista Projetos de Leis que tramitam na Câmara e no Senado Federal que buscam amenizar as diferenças de gênero nas organizações, fato que poderá contribuir para uma amostra maior de mulheres no comando de grandes corporações no Brasil.

\section{REFERÊNCIAS}

ATKINSON, Stanley M.; BAIRD, Samantha Boyce; FRYE, Melissa B. Do female mutual fund managers manage differently? Journal of Financial Research, v.26, n.1, p.1-18, 2003.

BARBER, Brad M.; ODEAN, Terrance. Boys will be boys: Gender, overconfidence, and common stock investment. The quarterly journal of economics, v.116, n.1, p.261-292, 2001.

BARUA, Abhijit et al. CFO gender and accruals quality. Accounting Horizons, v.24, n.1, p. 25-39, 2010.

BHARATH, Sreedhar T.; NARAYANAN, M. P.; SEYHUN, H. Nejat. Are women executives disadvantaged? 2009.

CHEN, Shuping, CHEN Xia, CHENG Qiang, SHEVLIN Terry. Are family firms more tax aggressive than non-family firms? Journal of Financial Economics, v.95, n.1, p.41-61, 2010.

CROSON, Rachel; GNEEZY, Uri. Gender differences in preferences. Journal of Economic literature, v.47, n.2, p.448-474, 2009.

DELOITTE. A jornada do CFO: O papel do lider de finanças na crise. Disponível em: <https://www2.deloitte.com/content/dam/ Deloitte/br/Documents/finance/cfo/AJornadadoCFO2016v2.pdf>. Acesso em 23 de outubro de 2016.

DESAI, Mihir A.; DHARMAPALA, Dhammika. Corporate tax avoidance and high-powered incentives. Journal of Financial Economics, v.79, n.1, p.145-179, 2006.

DWYER, Peggy D.; GILKESON, James H.; LIST, John A. Gender differences in revealed risk taking: evidence from mutual fund investors. Economics Letters, v.76, n.2, p.151-158, 2002.

DYRENG, Scott D.; HANLON, Michelle; MAYDEW, Edward L. The effects of executives on corporate tax avoidance. The Accounting Review, v.85, n.4, p.1163-1189, 2010.

FRANCIS, Bill B. et al. Are female CFOs less tax aggressive? Evidence from tax aggressiveness. The Journal of the American Taxation Association, v.36, n.2, p.171-202, 2014. 
GRAHAM, John R.; HARVEY, Campbell R.; PURI, Manju. Managerial attitudes and corporate actions. Journal of Financial Economics, v.109, n.1, p.103-121, 2013.

GRAHAM, John R.; TUCKER, Alan L. Tax shelters and corporate debt policy. Journal of Financial Economics, v.81, n.3, p.563-594, 2006.

HANLON, Michelle; HEITZMAN, Shane. A review of tax research. Journal of Accounting and Economics, v.50, n.2, p.127-178, 2010.

Hanlon, M. \& Slemrod, J. "What Does Tax Aggressiveness Signal? Evidence From Stock Price Reactions to News About Tax shelter involvement”, Journal of Public Economics 93(1-2), Elsevier, 126-141, 2009.

HUANG, Jiekun; KISGEN, Darren J. Gender and corporate finance: Are male executives overconfident relative to female executives? Journal of Financial Economics, v.108, n.3, p. 822-839, 2013.

Hausman, J.A. (1978). Specification Tests in Econometrics. Econometrica 46(6), 1251-1271.

INSTITUTO BRASILEIRO DE GOVERNANÇA CORPORATIVA. Relatório de Mulheres na Administração das Empresas Brasileiras Listadas, 2010 e 2011. Disponível em: <http://www.ibgc.org.br/userfiles/files/Mulheres_no_Conselho.pdf>. Acesso em 23 de outubro de 2016.

LANIS, Roman; RICHARDSON, Grant. The effect of board of director composition on corporate tax aggressiveness. Journal of Accounting and Public Policy, v.30, n.1, p.50-70, 2011.

MADALOZZO, Regina. CEOs e Composição do Conselho de Administração: a Falta de Identificação Pode Ser Motivo para Existência de Teto de Vidro para Mulheres no Brasil? CEOs and Board Composition: Can the Lack of Identification Be a Reason for Glass Ceilings in Brazil? Revista de Administração Contemporânea, v.15, n.1, p.126, 2011.

REGO, Sonja Olhoft; WILSON, Ryan. Equity risk incentives and corporate tax aggressiveness. Journal of Accounting Research, v.50, n.3, p.775-810, 2012.

REGO, Sonja Olhoft; WILSON, Ryan. Executive compensation, tax reporting aggressiveness, and future firm performance. In: Working Paper, University of Iowa. 2009.

RICHARDSON, Grant; TAYLOR, Grantley; LANIS, Roman. The impact of board of director oversight characteristics on corporate tax aggressiveness: An empirical analysis. Journal of Accounting and Public Policy, v.32, n.3, p.68-88, 2013.

ZEMZEM, Ahmed; FTOUHI, Khaoula. The effects of board of directors' characteristics on tax aggressiveness. Research Journal of Finance and Accounting, v.4, n.4, p.140-147, 2013. 